\title{
The German Primate Center - planning and realization of the institute
}

\author{
M. Schwibbe ${ }^{1, *}$ \\ ${ }^{1}$ German Primate Center (DPZ), Göttingen, Germany \\ * retired
}

Correspondence to: M. Schwibbe (m.schwibbe@gmail.com)

Received: 23 March 2015 - Revised: 14 May 2015 - Accepted: 19 May 2015 - Published: 10 June 2015

\begin{abstract}
It took almost 20 years from the first proposal for the foundation of a German primate centre to the final establishment of an institute for research on primates. Since 1964, the German science community had considered the idea of founding a national primate centre in the Federal Republic of Germany (West Germany) following existing models in the USA. In 1967, the project received a significant boost from the outbreak of the lethal Marburg virus infections, which was transmitted from African green monkeys to humans. However, a memorandum from Hans-Jürg Kuhn, at that time at the University of Frankfurt, facilitated a breakthrough in 1970. He conceived an interdisciplinary institute that would both conduct its own scientific research and be a service institute for other German institutions. After highly charged debates on a suitable location, the federal government decided on Göttingen, and in 1972 the University of Göttingen provided the necessary ground. With the certificate of incorporation in 1977, the federal government and the German state Lower Saxony appointed Professor Kuhn as the first scientific director. Based on his memorandum, a research and service institute was developed with several scientific departments associated with primate husbandry, and full operation began in 1984.
\end{abstract}

The originator of the idea to establish a primate centre in Germany is difficult to determine. However, it is certain that this idea had been discussed within the German science community since the early 1960s. At that time, a dozen national primate centres had already existed, including eight in the USA alone, as well as in the former Soviet Union, Japan and the Netherlands. Facilities in France and Italy were in the planning stage. Researchers in Germany saw an urgent need for action to avoid falling behind scientifically and to ensure their own supply of animals.

\section{The question of whether to build}

In a 1964 memorandum, Prof. Dr Helmut Hofer (Max Planck Institute for Brain Research, Frankfurt) drew attention to the need for increased support of primate research and presented initial ideas for the establishment of a German primate centre to the German Research Foundation (DFG Deutsche Forschungsgemeinschaft). Chaired by the President of the DFG Prof. Dr Julius Speer, a first meeting of selected scientific representatives took place in February 1965 at the Max Planck Society (MPG - Max-PlanckGesellschaft) in Munich. The Volkswagen (VW) Foundation of the State of Lower Saxony (Volkswagen Stiftung, VWStiftung, Stiftung Volkswagenwerk), as the third member of the national research funding group, was also involved at that time. Prof. Hofer, who had worked at the Tulane National Primate Research Center in Covington (Louisiana, USA) since 1965, contributed knowledge from his experience there (Fig. 1). ${ }^{1}$

At that time, a decentralized structure of primate research at three university towns in Germany was considered, in order to share the resources already available. This idea appeared to be an especially feasible solution from a political perspective. However, the experiences of other primate centres, particularly in the USA, showed that for both scien-

\footnotetext{
${ }^{1}$ Between 1965 and 1973, Hofer was a member of the scientific advisory board at the Yerkes National Primate Research Center in Atlanta, USA.
} 


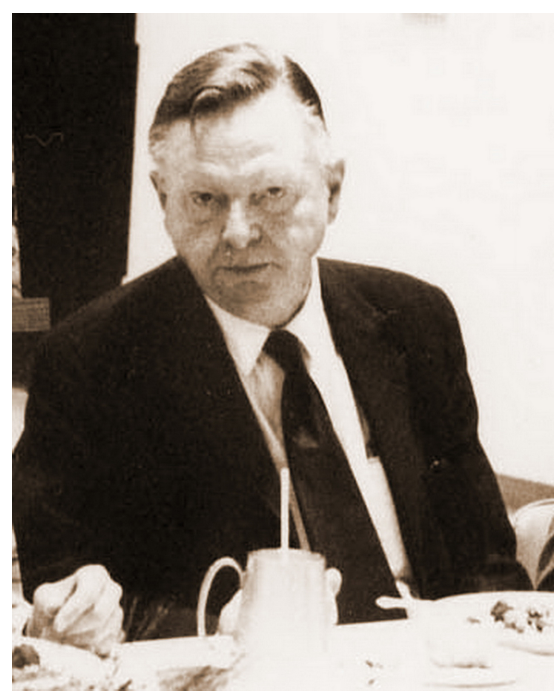

Figure 1. Prof. Dr Helmut Hofer was the first scientist to submit a memorandum on the establishment of a German primate centre in 1964 (picture from the Tulane National Primate Research Center in Covington, Louisiana, USA).

tific as well as economic reasons a central institute would be much more efficient.

In October 1965, an extended panel of experts unanimously voted to establish a primate centre in Germany. They proposed the realization of a central institute with a small staff and plenty of room for visiting scientists. An application to establish an institute for basic biomedical research on primates was submitted in February 1966 to the DFG, the VW Foundation, the President of the Max Planck Society and the Minister of Culture of of Hesse. The costs were estimated to be approximately DEM 450000 for human and material resources per year, and a one-off cost of about DEM 4.5 million for the building, facilities, laboratories, animal houses and scientific equipment.

In the same year, 1966, the International Primatological Society (IPS, founded in 1964) organized its first congress in Frankfurt under its secretary general, Prof. Hofer. With its university, the Senckenberg Society (e.g. Prof. Dr Dr Dietrich Starck, Director of the Senckenberg Anatomy, an institute of the Johann Wolfgang Goethe University Frankfurt and Prof. Dr Gustav Heinrich Ralph von Koenigswald, head of the Palaeoanthropology Department of the Senckenberg Research Institute) and the Max Planck Institute for Brain Research (e.g. Prof. Dr Heinz Stephan, head of the "Evolution of the Primate Brain" research group), Frankfurt was a centre of primatological research in the Federal Republic of Germany. The co-organizer of the congress, Dr Hans-Jürg Kuhn (staff member at the Senckenberg Institute of Anatomy, Associate Professor at the University of Frankfurt, Primatological Department), began to focus on research policy for the primatological sciences in Germany.

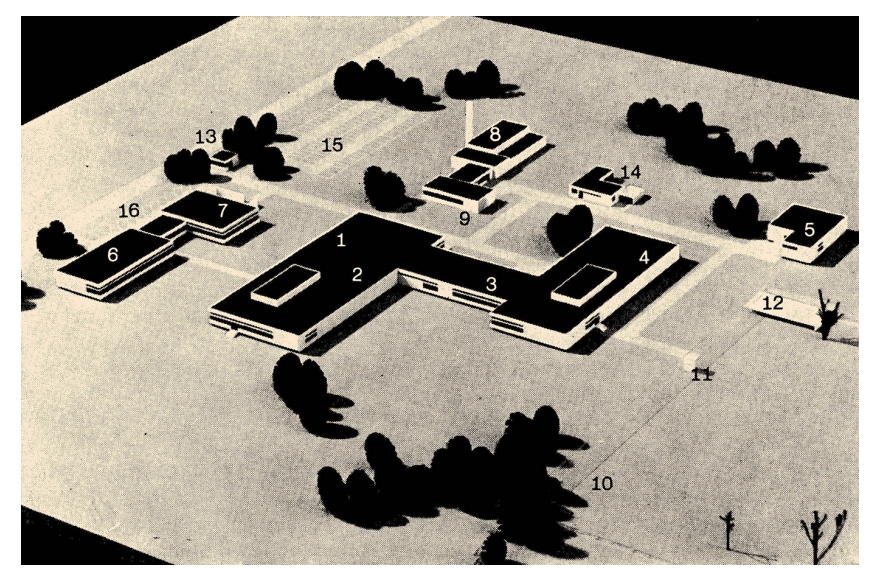

Figure 2. The first draft of the German Primate Center was designed by the Hanoverian architect Wilhelm-Heinrich Schrader in 1968, who was motivated to do so by his research expedition to the USA (picture from DPZ archive).

On behalf of the VW Foundation, a three-member delegation visited seven primate centres in the USA in February 1967. The mission resulted in an architectural design for the institute, now with an increased cost of approximately DEM 12.5 million (Fig. 2). This was calculated to require a maximum of 10 years to realize, based on the experiences of comparable centres in the USA.

Under its president, Prof. Dr Julius Speer, the DFG Senate convened a commission on primate research in October 1967. This commission consisted of 20 scientists from the Federal Republic of Germany, Austria, Switzerland and the Netherlands. ${ }^{2}$ Henceforth, this committee, chaired by Prof. Dr Hansjochem Autrum (Zoological Institute of the Ludwig Maximilian University of Munich) (Fig. 3), discussed all technical and scientific matters to be considered and decided to establish a primate centre. The commission especially emphasized the maintenance and restoration of the scientific competitiveness of research in Germany, especially in the field of experimental biomedicine. ${ }^{3}$

In 1967, the plans were strengthened by a lethal virus infection among animal caretakers from Marburg (Germany) and Belgrade (now Serbia). ${ }^{4}$ They were infected by contact with African green monkeys (Cercopithecus aethiops),

\footnotetext{
${ }^{2}$ It was the commission's task to advise the funding authorities on all matters during the constitution phase of the primate centre regarding the foundation of a holding company, the appointment of a scientific advisory board, staffing the first positions and on decisions about the first scientific projects. Furthermore, the commission developed a set of rules for working with primates.

3 "From the beginning, we were aware that German research had to catch up with the considerable advance of other countries in this field", Prof. Dr Hansjochem Autrum, chair of the Senate Commission recalled.

${ }^{4}$ In total, 7 out of 25 directly or indirectly infected people died of severe haemorrhagic fever caused by the Marburg virus.
} 


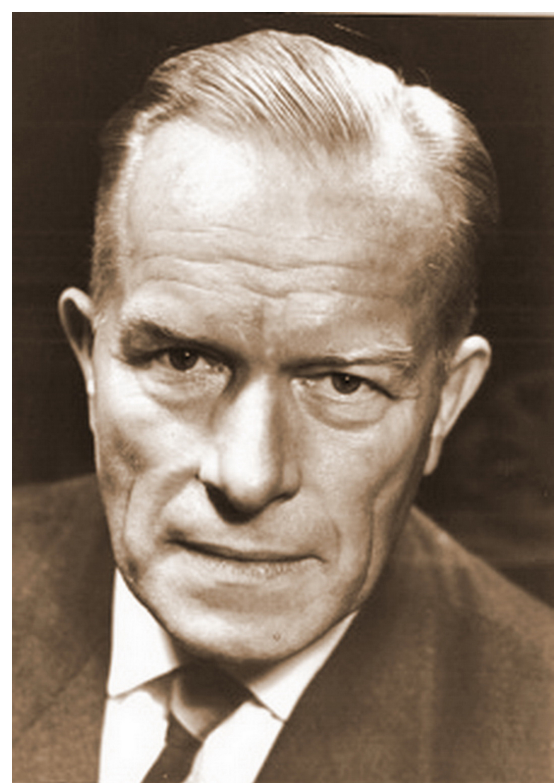

Figure 3. Prof. Dr Hansjochem Autrum chaired the DFG Senate Commission (picture from S. Autrum-Mulzer).

which had been imported from Uganda (Siegert et al., 1967). Therefore, the calls for a central facility in which the animals could be quarantined and medically examined after importation became much stronger (Der Spiegel, 1967).

In the meantime, the question arose as to whether it was more appropriate to establish a joint supranational centre for primatological research in Europe. Because of different national legislation and expected organizational problems, the considerations tended to be for decentralized facilities (1967 in Paris, 1969 in the Radiobiological Institute TNO, Rijswijk, the Netherlands). Although some European countries were at least willing to coordinate the establishment of national centres, none of the proposals resulted in concrete agreements. Therefore, the DFG Commission decided on an exclusively national approach.

\section{The answer: yes}

The realization of the "Primate Center" project was delayed, mainly owing to issues of financing and ownership. Therefore, the Senate Commission of the DFG requested comments from the German Council of Science and Humanities (WR - Wissenschaftsrat), the highest science policy committee of the Federal Republic and its states. The council in 1969 had clearly voted in favour of establishing a central institute of primatology in Germany, and pleaded for collective national financing. However, there was a major difference between the opinions of the DFG and those of the WR about the future orientation of a German primate centre. While the DFG preferred a balance between basic research and applied biomedical sciences, the WR stated that the centre should

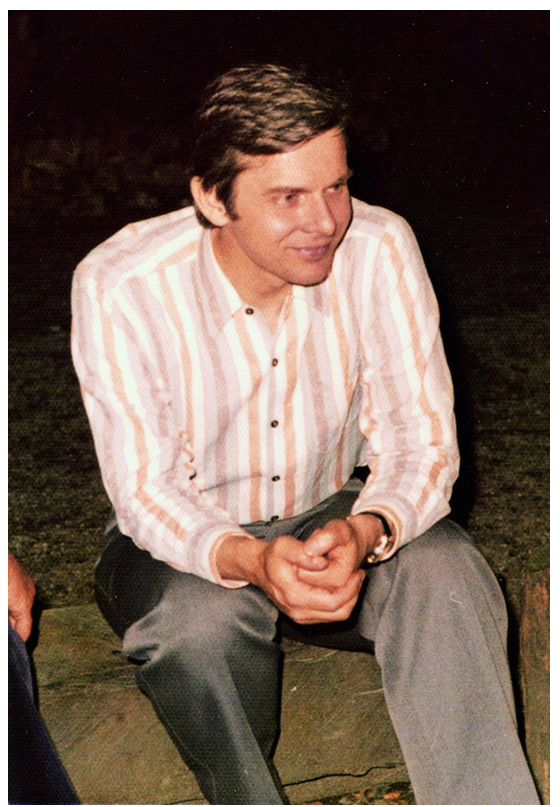

Figure 4. Dr Hans-Jürg Kuhn of the Senckenberg Institute in Frankfurt was appointed to the Senate Commission of the DFG in 1970 (picture from AST Text und Bild).

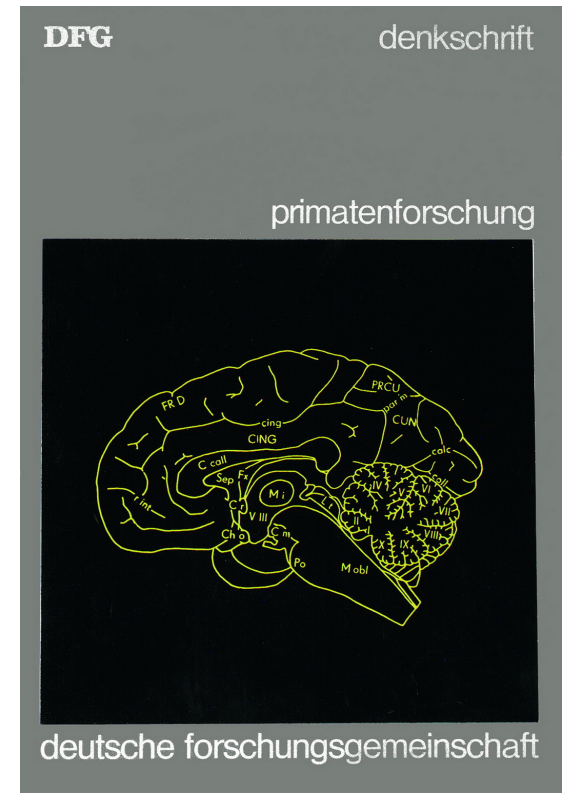

Figure 5. The cover of the DFG memorandum on primate research in Germany, written by Hans-Jürg Kuhn in 1970 (picture from DPZ archive).

primarily be conceived as a general primatological research institute.

In July 1970, Hans-Jürg Kuhn was appointed to the DFG Commission (Fig. 4). In the same year he submitted a memorandum entitled "Primatenforschung", which subsequently provided the basis for all further planning of the institute 


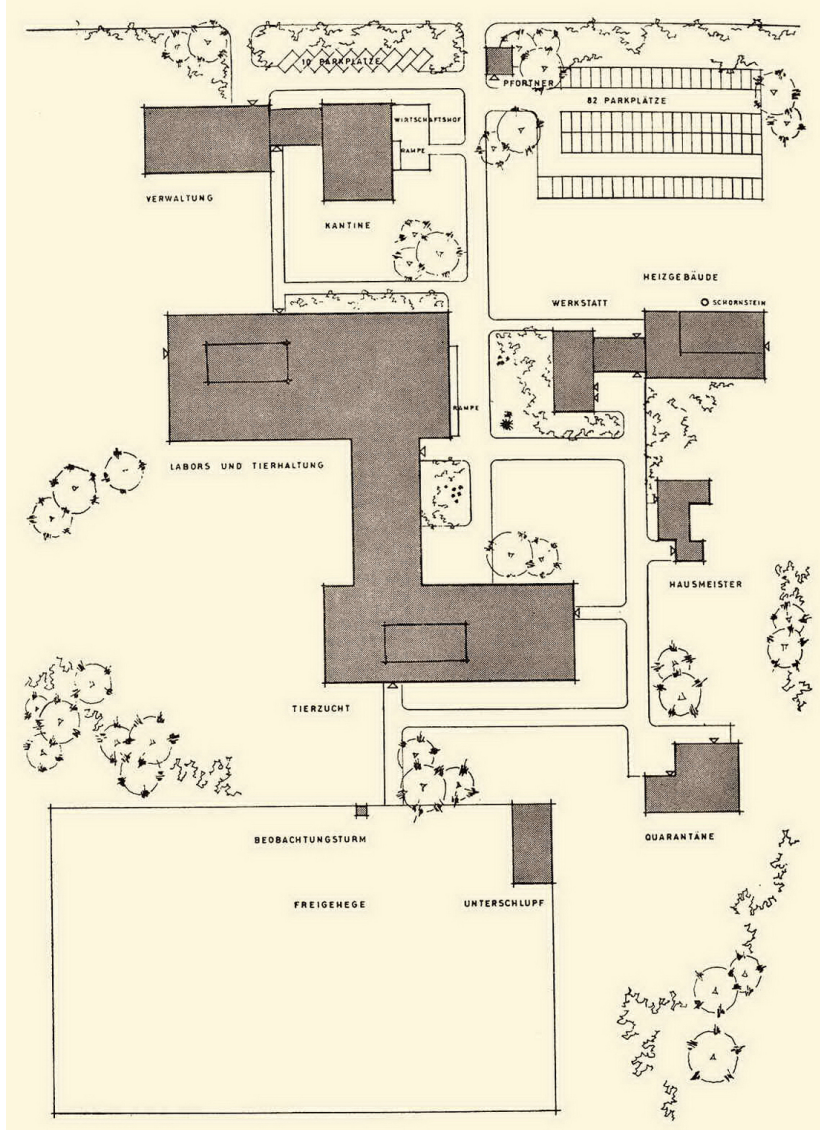

Figure 6. Construction design for the German Primate Center from the memorandum of 1970. It formed the basis for all further plans (picture from DPZ archive).

(Figs. 5, 6). Regarding the future orientation of the primate centre, Kuhn had a clear vision: "From the very beginning, one of the greatest difficulties in planning the centre was that everyone (including me) tended to evaluate the whole project according to the specific needs of his own profession and person, while the German Primate Center (Deutsches Primatenzentrum - DPZ) should be an interdisciplinary institute" (Kuhn, 1971, in a letter to the Ministry for Science and Art of Lower Saxony). In his memorandum, Kuhn not only pointed out the problem that German science would be left behind, but he also indicated the danger that German scientists would leave the country and continue their research activities in the USA. This would have resulted in the complete loss of primatological knowledge gained in the German research community.

Kuhn implicitly anticipated a term for the future orientation of the German primate centre, which was known 20 years later as a quality label for research and service in-

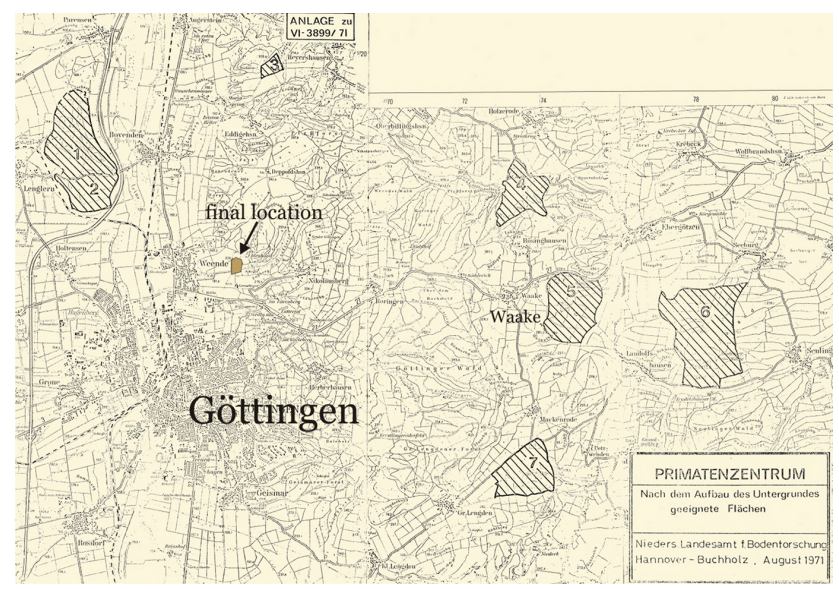

Figure 7. Map of area surrounding Göttingen from the Lower Saxony State Office for Soil Research, 1971 (modified with the final German Primate Center building site). A total of seven areas (hatched) around Göttingen were initially considered (picture from DPZ archive).

stitutes, a "Center of Competence and Reference". 5 Interestingly, other European primatologists followed the controversy over the orientation of a German primate centre. As a typical example, the ethologist and anthropologist Adriaan Kortlandt from the University of Amsterdam (NL) is quoted here: "Dear Mr. Kuhn, since your memorandum, from time to time I wonder in which directions the German primate centre is developing after all the difficulties, and whether it will be either a real centre for primatological sciences or only a medical research institute."

\section{The question of where}

The Senate Commission of the DFG developed a questionnaire, which was submitted to various interested municipalities and cities. Data were requested regarding the intended area, the road network and the connections with universities nearby. Frankfurt, Freiburg, Ulm and Göttingen in particular were determined to be appropriate locations. These university towns provided particularly suitable infrastructural preconditions for basic biomedical research. Moreover, for the proposed quarantine station, the spatial proximity of the cities to the Frankfurt airport was assumed to be a location advantage.

The choice for building the German Primate Center fell on Göttingen in 1970, because the state of Lower Saxony had also submitted a favourable financing offer. However, it was unforeseeable that the discussions on the final area in Göttingen would last for 7 years. Between 1970 and 1972, several sites in the neighbourhood of Göttingen were con-

\footnotetext{
5"After all, a scientist who intends to work with primates as laboratory animals needs a central facility where he can be informed about all the different aspects and problems.” (Kuhn, 1970)
} 
sidered, of which all proved to be unsuitable or undesired (Fig. 7). Finally, when all water and nature conservation law requirements had been examined, an area was chosen near the village of Waake, $8 \mathrm{~km}$ outside Göttingen.

Fierce resistance developed among the local villagers. Rumours circulated that mosquito bites could transfer lethal tropical diseases such as cholera, typhus, yellow fever and malaria from monkeys to humans and to livestock in the area. There was fear of contaminated monkey cadavers in the native forest, of contaminated drinking water and of odour nuisance caused by the incineration of dead animals. Home owners worried about loss of property values. "Either humans or monkeys", the inhabitants demanded, and they feared being greeted with "here comes the primate from Waake". It was even suspected that NATO was secretly behind the planning of the primate centre, and that the Warsaw Pact's response might one day be "Russian special forces appear and take over the entire area".

A scientist from the University of Göttingen sided with the protesters. He felt like a "puppet on a string" of the DFG and critized the proponents among his own colleagues: "What kind of primate centre will it be if it involves colleagues who conduct research on vermin or on hair loss?" The DPZ was a hobby of the "lice researcher" Kuhn, who had even accepted an invitation to chair the Department of Anatomy at the University of Göttingen in 1973, one of Kuhn's colleagues claimed. He stated that in Germany, nobody could be found who was at all qualified enough to head a primate centre (Der Spiegel, 1972).

The municipalities around Göttingen affected by the plan collected signatures of the residents and mobilized the national press. "No place for the monkeys?", asked the journalists. Headlines such as "Much ado about a thousand monkeys in Göttingen" and "Peasants' War" could be read in the newspapers, and a "war between monkeys and farmers" was taking place. A "nobel hostel for 2000 apes" and a "restricted area behind barbed wire" were predicted. A "foolish act in research funding" (German: Schildbürgerstreich), a "charade" (German: Affentheater), a "crying shame" (German: Affenschande), and a "monkey dance" were going on in Göttingen, according to the headlines.

Deeply disappointed about all the protests, the chairman of the DFG Senate Commission Prof. Autrum, resigned: "I would prefer the planning in Göttingen to fail, as soon as possible". The European science community worried about the continuing controversy: "If German research wants to attain a rank appropriate to its scientific capability, something must happen very soon", warned Dr Hans Balner, head of the TNO Radiobiological Institute, Rijswijk, the Netherlands, in March 1972 (Der Spiegel, 1972).

\section{The answer: here!}

In November 1972, the Senate Commission of the DFG recommended exploring the possibility of establishing the primate centre in a developmental area of Göttingen University. The government of Lower Saxony and the university soon agreed to build the DPZ in Weende, a site that was originally intended for an institute of veterinary medicine. The decision for this area was based "on the normative power of the facts. Preferably here and now, instead of never", stated the DFG Division Head Dr Rosemarie John.

"Lower Saxony holds tight to the monkeys" reported the press. There was an urgent need to remove the last "stones on the monkey trail". In 1976, the state government of Lower Saxony mandated the State Construction Authority of Göttingen (German: Staatshochbauamt) to proceed with the schedule. Subsequently, all considerations were based on the opinion of the Scientific Council of 1969 and the 1970 memorandum of Prof. Kuhn, with their already defined ideas about the plan and realization of scientific and technical requirements.

After the Marburg virus outbreak, another medical catastrophe occurred. In former Zaire and Sudan in 1976, the so-called Ebola virus broke out, infecting about 500 people with a mortality rate of approximately $75 \%$ (Report of an International Commission, 1978). In a laboratory in Porton Down, England, a staff member accidently infected himself from a pinprick containing an Ebola sample from a guinea pig (Emond et al., 1977). Because variants of the virus also emerge in cynomolgus monkeys (Macaca fascicularis), efficient epidemiological procedures against infections by imported animals and quarantine facilities were strongly required.

On 10 August 1977, the Federal Republic of Germany and the state of Lower Saxony finally signed a partnership agreement to establish the German Primate Center (DPZ). The DPZ was founded and organized as a limited company (DPZ GmbH). This date marks the official launch of the autonomous activities of the institute. Funding was shared, with $50 \%$ from the federal government and $50 \%$ from the states of the Federal Republic.

With the signing of the document, Prof. Dr HansJürg Kuhn took over the function of the scientific and technical director of the centre. A supervisory board was appointed to monitor the research policy of DPZ, and a scientific advisory board was established to counsel the directorship regarding the scientific orientation. In cooperation with the State Construction Authority, Prof. Kuhn developed concrete and detailed plans for the necessary buildings and equipment. In 1977, the Minister for Science and Art of Lower Saxony approved the spatial allocation program.

However, the start of construction was delayed, because the federal and state governments were not able to allocate the necessary financial resources. Prof. Kuhn, as a professor at the University of Göttingen and scientific director of 


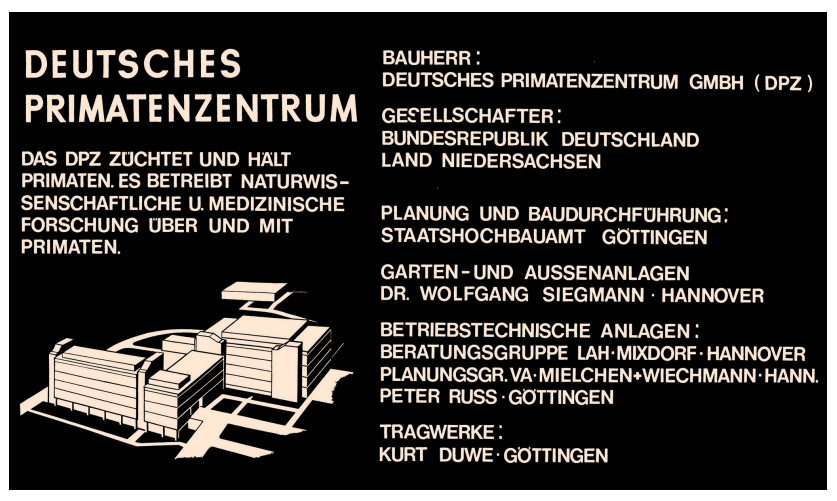

Figure 8. The information panel from the State Construction Authority. The foundation stone was laid on 11 May 1979 (picture from DPZ archive).

the DPZ, could exert some pressure on the funding authorities when he was offered a professorship at the University of Frankfurt in 1978. This threatened the state of Lower Saxony with the loss of both a professor and the director of the DPZ. But when the plans for some other national scientific projects were held up, funds were suddenly released for the initial construction of the primate centre. Prof. Kuhn remained in Göttingen, and on 11 May 1979, together with members of the supervisory board and representatives of the state government (Fig. 8), he laid the foundation stone for the DPZ.

The structure of the departments began to take shape. Prof. Kuhn successively established the departments of pathology and veterinary care, physiology, virology and immunology as well as reproductive biology. An animal house and an outdoor enclosure were intended to accommodate up to 1000 monkeys. The core of the primate colony consisted of 66 cotton-top tamarins (Saguinus oedipus) from the University of Göttingen, 100 tamarins (Saguinus fuscicollis and Saguinus labiatus) from the Monell Institute, Philadelphia, USA, 13 hamadryas baboons (Papio hamadryas) from the Frankfurt Zoo and 80 rhesus monkeys (Macaca mulatta) from Cayo Santiago, Puerto Rico. They were intended to serve for breeding and supplying both the centre and external scientists with animals. With a cooperation agreement between the DPZ and the Pan American Health Organization (PAHO), which included the utilization of a primate research station in Iquitos, Peru, Prof. Kuhn initiated the field research activities of the DPZ.

The scientists and the management were still housed in rooms rented from the University of Göttingen. Progressively, the scientists, the technical staff and the animals moved into the completed facilities. On 12 April 1984, the official inauguration of the DPZ took place. ${ }^{6}$

\footnotetext{
${ }^{6}$ It took about 8 years between the fundamental decision to establish the US primate centres and their completion. In contrast, for the German Primate Center a total of 18 years elapsed between
}

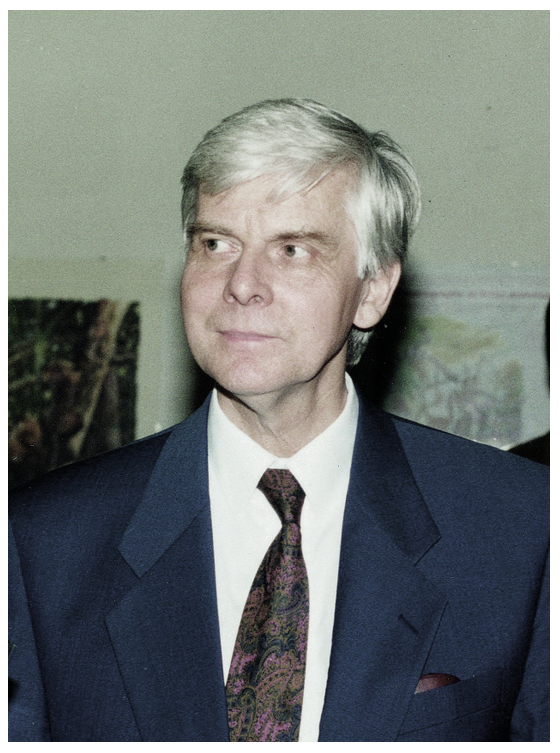

Figure 9. Prof. Dr Hans-Jürg Kuhn was the first scientific director of the German Primate Center and headed the institute from 1977 to 1996 (picture from DPZ archive).

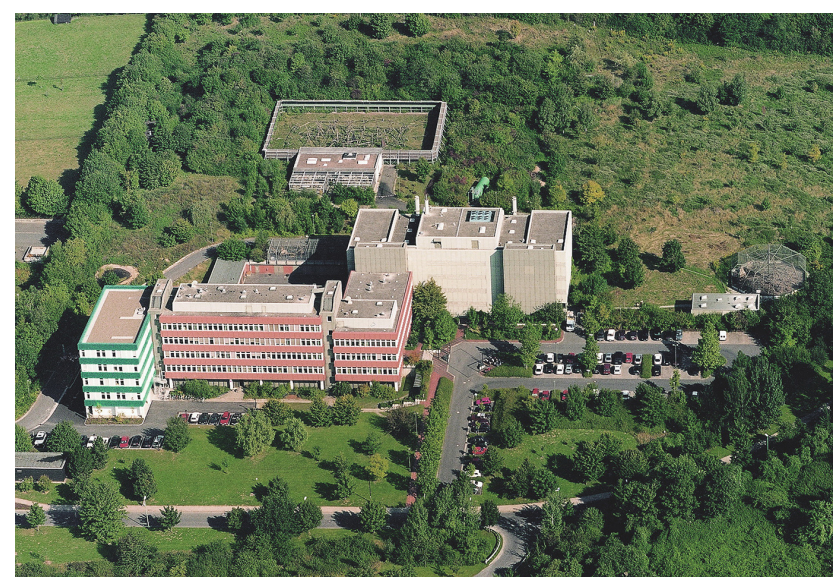

Figure 10. Bird's-eye view of the German Primate Center with its three facility wings, from the left: office wing, laboratory wing, functional wing and the animal house, with the outdoor enclosure at the rear (picture from DPZ archive, 2001).

Prof. Kuhn had attained his goals (Fig. 9). The orientation of the institute was now clearly defined; it was an interdisciplinary research institute with service functions for German sciences (Fig. 10). He headed the institute until 1996 and integrated it firmly into the German research community. The professorship status of the department's heads closely connects the DPZ with the University of Göttingen. Coordinating the European Primate Network (EUPRIM-Net), the in-

submitting the application to the research funding organizations in 1966 and the inauguration in 1984. 
stitute is deeply embedded in the European research on primates.

Kuhn often recommended to his students and young colleagues that "You always have to know what you want, and do not allow yourself to be misled", considering his own experiences with planning and establishing the DPZ.

Edited by: E. Fuchs

Reviewed by: F.-J. Kaup and one anonymous referee

\section{References}

Der Spiegel: Medizin/Affen-Seuche: Spur im Dunkel, Nr. 37, available at: http://www.spiegel.de/spiegel/print/d-46369459. html (last access: 28 May 2015), 1967.

Der Spiegel: Forschung: Primat aus Waake, Nr. 12, available at: http://www.spiegel.de/spiegel/print/d-43020091.html (last access: 28 May 2015), 1972.

Emond, R. T., Evans, B., Bowen, E. T., and Lloyd, G.: A case of Ebola virus infection, Br. Med. J., 2, 541, 1977.

Kuhn, H.-J.: Denkschrift zur Lage der Primatenforschung in Deutschland, Deutsche Forschungsgemeinschaft DFG, Bonn, Germany, 1970.

Schwibbe, M.: 25 Jahre Deutsches Primatenzentrum DPZ, Göttingen, Germany, 2002.

Siegert, R., Shu, H.-L., Slenczka, W., Peters, D., and Müller, G.: Zur Ätiologie einer unbekannten, von Affen ausgegangenen menschlichen Infektionskrankheit [On the hitherto unknown infectious disease originating in monkeys: The Marburg virus disease], Dtsch. med. Wochenschr., 92, 2341-2343, 1967.

Report of an International Commission: "Ebola Haemorrhagic Fever in Zaire, 1976”, B. World Health Organ., 56, 271-293, 1978. 